\title{
Protrusion of the tongue in burned bodies as a vital sign?
}

\author{
Michael Bohnert
}

Received: 19 August 2013 / Accepted: 10 October 2013 / Published online: 27 October 2013

(C) Springer-Verlag Berlin Heidelberg 2013

Bernitz et al. published a paper on the protrusion of the tongue in burned bodies and were of the opinion that this was an indicator of vital burning [1]. The authors reported that in 63 of 107 fire fatalities, protrusion of the tongue was observed, whereas in 27 cases, this phenomenon was not seen. The authors compared this parameter with the presence of soot deposits in the respiratory tract and an elevated $\mathrm{CO}-\mathrm{Hb}$ content in the corpse blood - the characteristic parameters of vitality. They found that in the vast majority of the cases with protrusion of the tongue, soot aspiration and $\mathrm{CO}-\mathrm{Hb}$ values $>10 \%$ were also present. According to the authors, subsequently performed statistical tests (Fisher's exact test, Mann-Whitney test, Kolgorov-Smirnov test) confirmed that protrusion of the tongue was a sign of vitality.

This is a very bold conclusion. The authors ignore in their argumentation that most fire-related deaths show signs of vitality [1-6]. This has not only been demonstrated in various studies, but is also true in the 107 cases presented by Bernitz et al. [1]. Statistical comparison of two groups of such different sizes (vital versus avital burning) is questionable. However, in the discussion, this methodological problem is not even mentioned. Moreover, protrusion of the tongue and soot aspiration are findings very often seen in fire fatalities. For that reason alone, the probability that both parameters occur simultaneously is very high, although the mere coincidence of two parameters does not mean that they are of equal validityin this case, that they are signs of vital exposure to fire.

Apart from looking for a correlation between tongue protrusion and internal signs of vitality, one could then also look for a correlation between charring of the skin, pugilistic attitude or fire-related amputations and internal signs of

Letter to the Editor concerning on the paper "Tongue protrusion as an indicator of vital burning" by Bernitz et al.

M. Bohnert $(\bowtie)$

Institute of Forensic Medicine, University of Würzburg,

Versbacher Str. 3, Würzburg, Germany

e-mail: michael.bohnert@uni-wuerzburg.de vitality. In all probability, this approach would also produce positive correlations. By the way, the application of statistical methods would show the same significant results if the hypothesis were "Protrusion of the tongue is no vital sign and thus simultaneous soot aspiration is not either." This obviously absurd statement could also be proved by the data material and tests used by the authors.

In addition, there is no pathophysiological explanation whatsoever why protrusion of the tongue should be a sign of vitality. The statement that, after death, no physiological processes are going on which might explain protrusion of the tongue, does not really help, as it goes without saying that physiological processes always occur before death. Obviously, the authors were also aware (as the last sentence of the discussion chapter shows) that the pathophysiological processes should also be recorded. On the other hand, the assumption mentioned in the introduction that this may be a postmortem artefact due to the heat-related shrinking of the cervical soft tissue [7] is not addressed either in the methodology part or in the discussion. The essential parameter in this context would be to what extent the cervical soft tissue was burned, but this was not even recorded in the present study.

\section{References}

1. Bernitz H, van Staden PJ, Cronje CM, Sutherland R (2013) Tongue protrusion as an indicator of vital burning. Int J Legal Med. doi:10.1007/s00414-013-0861-4

2. Bohnert M, Werner CR, Pollak S (2003) Problems associated with the diagnosis of vitality in burned bodies. Forensic Sci Int 135:197-205

3. Fieguth A, Kistenmacher L, Tröger HD, Kleemann WJ (1997) Todesfälle bei Hitzeeinwirkung. Arch Kriminol 200:79-86

4. Gerling I, Meissner C, Reiter A, Oehmichen M (2000) Death from thermal effects and burns. Forensic Sci Int 115:33-41

5. Maxeiner H (1988) Umstände und Befunde bei 202 Brandtodesfällen. Beitr Gerichtl Med 46:313-325

6. Rogde S, Olving JH (1996) Characteristics of fire victims in different sorts of fire. Forensic Sci Int 77:93-99

7. Bohnert M (2004) Morphological findings in burned bodies. In: Tsokos M (ed) Forensic pathology reviews. Humana, Totowa, pp 3-27 